\title{
ATIVIDADE INSETICIDA DE EXTRATOS VEGETAIS E DO ÓLEO DE NIM SOBRE ADULTOS DE ALPHITOBIUS DIAPERINUS PANZER (COLEOPTERA, TENEBRIONIDAE)
}

\author{
A.M. Marcomini' ${ }^{1}$ L.F.A. Alves ${ }^{2}$, A.K. Bonini ${ }^{2}$, N.R. Mertz ${ }^{3}$, J.C. dos Santos ${ }^{3}$
}

${ }^{1}$ Universidade deSão Paulo, Escola Superior de Agricultura “Luiz de Queiroz", Departamento de Entomologia e Acarologia, Laboratório de Resistência de Plantas a Insetos e Plantas Inseticidas, Av. Pádua Dias, 11, CEP 13418-900, Piracicaba, SP, Brasil. E-mail: ammarcomini@yahoo.com.br

\section{RESUMO}

A utilização de plantas inseticidas tem se mostrado uma ferramenta promissora para controle de insetos, contudo ainda há muito pouco no que diz respeito ao efeito sobre Alphitobius diaperinus (Panzer). Portanto, o objetivo do trabalho foi avaliar a atividade inseticida de extratos vegetais visando o controle desse inseto em aviários. Foram testados extratos etanólicos (E), diclorometânicos (D), hexânicos (H) e aquosos (A) deAnnonamuricata, Chenopodiumambrosioides, Eucalyptus grandis, Melia azedarach, Ocimum basilicum, Ruta graveolens e Tagetes erecta, e um óleo comercial à base de nim, Azadirachta indica (Dalneem $\left.{ }^{\circledR}\right)$. Os extratos e o óleo foram diluídos na concentração de $10 \%$ e pulverizados sobre os insetos, mantidos em placas de Petri. O controle recebeu aplicação de água destilada. Os tratamentos mais eficientes foram óleo comercial de $A$. indica (97,5\%), extrato de R. graveolens (E) (61,3\%), C. ambrosioides (H) (32,5\%) e de folhas de $M$. azedarach (E e D) (ambos 26,3\%). Comparou-se também a aplicação direta do óleo sobre o inseto e aplicação na superfície com a qual o inseto ficaria em contato, sendo maior a eficiência quando pulverizado sobre os insetos $(100 \%)$ em relação ao contato com superfície tratada $(40,9 \%)$. Comparando-se diferentes concentrações do óleo pulverizado nos insetos, observou-se relação direta entre atividade inseticida e concentração utilizada, não havendo efeito apenas na menor concentração $(0,1 \%)$. Contudo, o óleo não apresentou atividade sobre os insetos quando aplicado na cama do aviário.

PALAVRAS CHAVE: Produção animal, plantas inseticidas, Azadirachta indica, controle de pragas.

\section{ABSTRACT}

INSECTICIDAL ACTIVITY OF PLANT EXTRACTS AND NEEM OIL ON ALPHITOBIUS DIAPERINUS PANZER ADULTS (COLEOPTERA, TENEBRIONIDAE). The use of insecticidal plants seems to be a promising method for insect control, however there are few studies in relation to their effect on Alphitobius diaperinus (Panzer). The present study was carried out to evaluate the insecticidal activity of plant extracts for the alternative control of this insect in poultry houses. Tests were made using ethanolic (E), dichlorometanic (D), hexanic $(\mathrm{H})$ and aqueous $(\mathrm{A})$ extracts from Annona muricata, Chenopodium ambrosioides, Eucalyptus grandis, Melia azedarach, Ocimum basilicum, Ruta graveolens and Tagetes erecta, and a commercial oil from Azadirachta indica (Dalneem $\left.{ }^{\circledR}\right)$. Extracts and oil were diluted at $10 \%$ and sprayed on the insects, kept in Petri dishes, and the control consisted of distilled water. The most effective treatments were: A. indica commercial oil (97.5\%), extracts from $R$. graveolens (E) (61.3\%), C. ambrosioides $(\mathrm{H})(32.5 \%)$ and leaf extracts from $M$. azedarach (E and D) (both $26.3 \%$ ). The direct application of the neem oil on the insect was also tested in comparison to its application on the surface with which the insect would be in contact; in this case the efficiency was higher when sprayed on the insects $(100 \%)$ in relation to the contact with treated surface $(40.9 \%)$. Comparing different concentrations of the neem oil sprayed on the insects, a direct relation between insecticidal activity and concentration was observed, although no effect was observed at the lowest concentration $(0.1 \%)$. However, the neem oil did not present activity on the insects when applied in the poultry litter.

KEY WORDS: Animal production, insecticidal plants, Azadirachta indica, pest control.

\footnotetext{
${ }^{2}$ Universidade Estadual do Oeste do Paraná, Centro de Ciências Biológicas da Saúde, Cascavel, PR, Brasil.

${ }^{3}$ Universidade Federal de Lavras, Departamento de Entomologia, Lavras, MG, Brasil.
} 


\section{INTRODUÇÃO}

O cascudinho dos aviários, Alphitobius diaperinus Panzer(1797) (Coleoptera, Tenebrionidae), disseminouse pelos aviários devidoàs condiçõesfísicase climáticas favoráveis para sua proliferação, como temperatura e umidadeconstantes eelevadas, práticas de reutilização da cama e fácil acesso ao alimento (STEELMAN, 1996; Chernaki-Lefferr; Almeida, 2001; Chernaki-LefFer et al., 2001). Grandes populações desse inseto são encontradas normalmente sob comedouros, já que a ração das aves é o seu alimento principal, além de aves mortas (AxTell; Arends, 1990). Ovos, larvas, pupas e adultos podem ser encontrados sob os comedouros e no solo, podendo atingir, neste caso, até $0,8 \mathrm{~m}$ de profundidade (CHeRNAKI-LeFFer et al., 2001).

A. diaperinus é um reservatório de diversos patógenos de importância para a avicultura, além de prejudicar a conversão alimentar e o ganho de peso quando a ave o ingere no lugar de ração (Goodwin; WALTMAN, 1996; CHERNAKI-LefFeret al., 2001; CHERNAKILEFFER et al., 2002; VITTORI et al., 2007).

Tentativas de controle têm sido feitas por meio de práticas de manejo e utilização de inseticidas químicos, sendo os organofosforados e os piretroides os mais utilizados (CHERNAKI-LefFeret al., 2001). Contudo, o sucesso de tal método é relativo, além de causar problemas como desenvolvimento de populações de insetos resistentes, contaminação ambiental, risco de intoxicação do produtor e também das aves (ARENDS, 1987; LAMBKIN, 2005; Alves et al., 2006).

Alguns relatos na literatura mostram que extratos de algumas plantas mostraram-se eficientes contra $A$. diaperinus. TABAssum et al. (1998) avaliaram uma formulação de nim (Azadirachta indica A. Juss) com butóxido de piperonila como sinergista (RB-a + PBO + Tx-100) em comparação a um piretroide, quanto ao efeito de contato sobre adultos. Ambos os produtos apresentaram atividade inseticida, entretanto a dose letal do nim foi maior. SzCZEPANIK (2001) testou um produto comercial à base de nim contra larvas de $A$. diaperinus tratando a ração que servia de alimento ao inseto; os resultados mostraram que houve interferência tanto na sobrevivência quanto no desenvolvimento das larvas. O óleo de sementes de nim causou também repelência sobre o cascudinho, assim como óleos de Ricinus communis L., Sesamum sp. e Aphanamixis polystachya (Wall.) Parker, com destaque para a última, que pertence à família Meliaceae, assim como o nim (RAHMAN et al., 2001). HASAN et al. (2002) avaliaram a atividade de Derris indica sobre larvas de A. diaperinus em combinação com triflumuron (um regulador de crescimento de insetos) e com Bacillus thuringiensis. Verificaram que houve redução na pupação e no aparecimento de adultos com ambas as combinações, principalmente com triflumuron.

Atualmente, é vasto o número de trabalhos referentes ao efeito de pós e extratos vegetais sobre vários insetos. Pós de várias plantas apresentaram efeito repelente sobre Acanthoscelides obtectus Say (Coleoptera; Bruchidae), dentre elas Eucalyptus citriodora Hook, Ocimum basilicum L., O. minimum L., Ruta graveolens L. e Melia azedarach L. (Mazzonetto; VendRAMIM, 2003). M. azedarach apresentou também efeito antialimentar sobre a vaquinha do feijoeiro, Diabrotica speciosa Germar (Coleoptera; Chrysomelidae) (CARValho; Ferreira, 1990).

Os extratos hexânico e etanólico de frutos de Chenopodium ambrosioides L. apresentaram efeito inseticida sobre adultos de Sitophilus zeamais Mots. (Peterson et al., 1989). Extratos alcoólicos de R. graveolens, Tagetes patula L.e Eucalyptus spp., aplicados na forma de vapor, causaram mortalidade acima de $80 \%$ de adultos de Sitophilus spp.(Almeida etal.,1999). Plutella xylostella L. (Lepidoptera; Plutellidae) foi susceptível a atividade inseticida de extratos de Annona squamosa L. (LeAtemiA; ISMAN, 2004) e de A. indica (Torres et al., 2001). Formulações comerciais de nim (Agroneem ${ }^{\circledR}$, Ecozin ${ }^{\circledR}$ e Neemix ${ }^{\circledR}$ ) eumextratodesementes apresentaramefeito deterrente de oviposição e alimentação, além de repelência, sobre Anthonomus grandis grandis Boheman (Coleoptera; Curculionidae) (SHOwler et al., 2004).

Assim, este trabalho foi desenvolvido com o objetivo de avaliar o efeito de diferentes extratos vegetais sobre o cascudinho, além de comparar formas de aplicação e concentrações, visando sua utilização futura em campo.

\section{MATERIAL E MÉTODOS}

Foram utilizados adultos de $A$. diaperinus, provenientes de um aviário comercial no Município de Cascavel, PR, mantidos em laboratório em condições ambiente $\left(25 \pm 1^{\circ} \mathrm{C}\right.$ e fotoperíodo natural $)$ em recipiente plástico ventilado, contendo cama de aviário e ração para aves, até a realização dos experimentos, por cerca de cinco dias.

Avaliação de extratos vegetais. As plantas utilizadas para obtenção dos extratos a serem testados foram escolhidas por já terem apresentado ação inseticida contra outros insetos (Quadro 1). Os extratos foram fornecidos pela equipe do Laboratório de Fitoquímica da Universidade Estadual do Oeste do Paraná. Com exceção do nim, as plantas foram coletadas no Município de Cascavel, PR, e região, e foram identificadas por especialistas do Herbário da Universidade Estadual do Oeste do Paraná. As plantas foram secas à sombra e, em seguida o material foi moído em moinho de facas utilizando peneiras de 10 , 20 e 30 mesh. 
Quadro 1 - Plantas e respectivas partes utilizadas para obtenção de extratos avaliados contra adultos deA.diaperinus.

\begin{tabular}{|llll|}
\hline Planta & Nome popular & Parte & Solventes \\
\hline Annona muricata & Graviola & Raízes & E, D \\
Azadirachta indica & Nim & Sementes & A \\
Chenopodium ambrosioides & Erva-de-santa-maria & Ramos & H, A \\
Eucalyptus grandis & Eucalipto & Folhas & E, D, A \\
Melia azedarach & Cinamomo & Folhas & E, D, H, A \\
Melia azedarach & Cinamomo & Frutos & E, A \\
Ocimum basilicum & Alfavaca & Folhas & E, D, H, A \\
Ruta graveolens & Arruda & Ramos & E, A \\
Tagetes erecta & Cravo-de-defunto & Flores & E, D, H, A \\
\hline
\end{tabular}

*Produto comercial à base de óleo de sementes (Dalneem $\left.{ }^{\circledR}\right)$.

$\mathrm{E}=$ etanol, $\mathrm{D}=$ diclorometano, $\mathrm{H}$ = hexano, $\mathrm{A}$ = água

O pó obtido foi submetido à extração a quente por solventes orgânicos, em aparelho de Soxleth, sendo utilizados quatro solventes: água, etanol, diclorometano e hexano, devido às diferenças na capacidade de extração que eles apresentam em razão da diferença de afinidade deles em relação aos compostos das plantas (Costaetal., 2004). Posteriormente, o solvente foi eliminado utilizando-se um rotaevaporador. O resíduo foi armazenado em recipiente de vidro e mantido em refrigerador para conservação e proteção da incidência de luz até a utilização, por um período não superior a 30 dias.

Os extratos aquosos foram obtidos por imersão do póvegetalemágua destilada, agitaçãoe repouso por 24 horas, com posterior filtração com tecido de voil (RodríGUEZ; VENDRAMIM, 1996). Como não se tinha conhecimento dos efeitos desses extratos em relação ao cascudinho, optou-se pela concentração uniforme de 10\% (peso do pó/volume deágua) para todos os extratos, obtida pela adição de água destilada e espalhante adesivo (Tween $80^{\circledR} 0,01 \%$ ). Ressalta-se que a concentração adotada é elevada e pode estar acima do limite da comerciabilidade, porém optou-secomo forma dese detectar eventual atividade inseticida.

Previamente à realização do trabalho, testou-se o efeito de diferentes concentrações de acetona diluída em água destilada sobre os insetos, de forma que a concentração de $10 \%$ mostrou-se segura, não provocando alterações ou mortalidade. Assim, $500 \mathrm{mg}$ de cada extrato foram solubilizados em $1,5 \mathrm{~mL}$ de acetona, resultando na solução estoque, que foi em seguida diluída em água destilada estéril com espalhante adesivo para obtenção da concentração de $10 \%$ (volume da solução estoque/volume de água), antes da aplicação sobre os insetos. Assim, a concentração final de acetona em todos os extratos correspondeu a $10 \%$. O óleo comercial de A. indica foi apenas diluído em água destilada para a aplicação, também na concentração de $10 \%$.
Logo após o preparo, os extratos foram pulverizados diretamente sobre os insetos, dispostos em uma placa de Petri, com auxílio de um pulverizador acoplado a uma bomba vácuo-pressurizadora, com pressão constante de $10 \mathrm{lb}$ de saída, sendo $1 \mathrm{~mL}$ para cada repetição. Os insetos foram então transferidos para outra placa de Petri e mantidos em câmara B.O.D. $\left(26 \pm 1^{\circ} \mathrm{C}\right.$ e fotofase $\left.14 \mathrm{~h}\right)$, alimentados com ração para aves, 24 horas após o tratamento, sendo 2 g para cada repetição. Foram preparadas quatro repetições para cada um dos tratamentos, com 20 insetos adultos cada uma, em delineamento inteiramente casualizado. O controle consistiu da aplicação de água destilada estéril com espalhante adesivo sobre os insetos, seguindo o mesmo procedimento adotado para os demais tratamentos. A avaliação de mortalidade foi realizada diariamente, durante sete dias, considerando-se mortos aqueles insetos que não respondiam ao toque de uma pinça.

Comparação entre métodos de aplicação. Otratamento com melhor resultado no experimento anterior foi selecionado para comparação de dois métodos de aplicação do extrato sobre $A$. diaperinus: pulverização direta sobre o inseto, conforme utilizado anteriormente, e pulverização sobre uma superfície com a qual o inseto entraria em contato, formando uma camada residual, denominadas, respectivamente, pulverização e contato. Em ambos os casos, a aplicação foi feita com auxílio de um pulverizador acoplado a uma bomba vácuo-pressurizadora, com pressão constante de 10 lb de saída. Para o método de pulverização, foram adotados os mesmos procedimentos descritos anteriormentee, no método de contato, o mesmo volume do extrato foi pulverizado sobre a placa de Petri, formando uma camada residual. Após a secagem completa das placas sob ventilação forçada de uma câmara de fluxo laminar (cerca de duas horas), os insetos foram transferidos para elas, onde foram mantidos durante todo o experimento. Cada método teve 
a respectiva testemunha, que consistiu de aplicação de água destilada.

Para cada método foram preparadas 10 repetições, cada uma contendo 20 insetos adultos, em delineamento inteiramente casualizado. Os insetos receberam alimento apenas 24 horas após a aplicação, para evitar que eventualmente se limpassem na ração ou que esta impedisse seu contato com o resíduo do extrato. Os insetos foram mantidos em câmara BOD (26 $\pm 1^{\circ} \mathrm{C}$ e fotofase $\left.14 \mathrm{~h}\right)$, durante 10 dias, sendo avaliados diariamente quanto à mortalidade.

Avaliação em diferentes concentrações. $O$ tratamento selecionado foi também testado em diferentes concentrações, seguindo o método de aplicação mais eficiente obtida no experimento anterior. As concentrações testadas foram 0,1, 1, 5 e 10\%, sendo cinco repetições com 20 insetos adultos em cada, em delineamento inteiramente casualizado. Os insetos foram mantidos em câmara BOD (26 $\pm 1^{\circ} \mathrm{C}$ e fotofase $\left.14 \mathrm{~h}\right)$, e as avaliações foram feitas durante 7 dias.

Atividade em cama de aviário. O tratamento selecionadofoiaplicado posteriormenteem cama usada de aviário, utilizando-se a concentração mais satisfatória obtida anteriormente. A aplicação foi feita diretamente na cama, colocando-se os insetos em seguida (préinfestação) ena cama já com os insetos (pós-infestação).

Para tal, foram utilizados potes plásticos de $17 \times$ $12 \times 12 \mathrm{~cm}(\mathrm{C} \times \mathrm{A} \times \mathrm{L})$, onde foram colocados $5 \mathrm{~cm}$ de cama usada de aviário e ração esterilizada para aves. Em seguida, foram pulverizados $8,5 \mathrm{~mL}$ de solução do extrato, equivalente a aproximadamente $0,84 \mathrm{~L} / \mathrm{m}^{2}$, tendo-se como base metade do volume de calda recomendado para o controle químico do cascudinho. Em análise prévia, verificou-se que este volume era suficiente para molhar uniformemente a superfície da cama sem excesso, o que poderia favorecer o crescimento de fungos saprófitos, interferindo no resultado. O controle não recebeu nenhuma aplicação. Foram utilizadas oito repetições por tratamento, com cerca de 160 adultos cada, em delineamento inteiramente casualizado. Os potes foram mantidos em B.O.D. (26 $\pm 1^{\circ} \mathrm{C}$ e fotofase $14 \mathrm{~h}$ ), durante 10 dias, após o que foi feita a contagem de insetos vivos e mortos.

Análise dos dados. Os dados de mortalidade foram corrigidos pela fórmula deSchneider-Orelli (ALVES et al., 2006) (exceto no primeiro experimento, em que não houve mortalidade no controle) e transformados em $\operatorname{arcsen} \sqrt{x / 100}$, antes das análises. Os dados foram analisados quanto à variância pelo teste $\mathrm{F}$ e as médias foram comparadas entre si pelo teste de Tukey no teste de avaliação de extratos vegetais, e pelo teste $\mathrm{t}$, para os testes de métodos de aplicação e atividade em cama de aviário $(\alpha=0,05)$, utilizando o programa SAS versão 9.1 (SAS InSTituTe, 2004). Para o teste de concentrações foi feita análise de regressão utilizando o software Microsoft Office Excel® 2003.

\section{RESULTADOS E DISCUSSÃO}

Avaliação de extratos vegetais. Apenas cinco tratamentos diferiram do controle, sendo óleo comercial de A. indica $(97,5 \%)$, extrato etanólico de R. graveolens (61,3\%), extrato hexânico de C. ambrosioides (32,5\%) e extratos etanólico e diclorometânico de folhas de $M$. azedarach (ambos 26,3\%) (Tabela 1).

Tabela 1 - Mortalidade média ( $\pm E P)$ de adultos de $A$. diaperinus tratados com diferentes extratos vegetais, após sete dias $\left(26 \pm 1^{\circ} \mathrm{C}\right.$ e fotofase $\left.14 \mathrm{~h}\right)$.

\begin{tabular}{lc}
\hline Tratamento & Mortalidade $(\%)$ \\
\hline Azadirachta indica - A & $97,5 \pm 0,06 \mathrm{a}$ \\
Ruta graveolens - E & $61,3 \pm 0,01 \mathrm{~b}$ \\
Chenopodium ambrosioides - H & $32,5 \pm 0,04 \mathrm{bc}$ \\
Melia azedarach (folha) - D & $26,3 \pm 0,09 \mathrm{bcd}$ \\
Melia azedarach (folha) - E & $26,3 \pm 0,06 \mathrm{bcd}$ \\
Annona muricata - D & $10,0 \pm 0,03 \mathrm{cde}$ \\
Chenopodium ambrosioides - A & $8,6 \pm 0,04 \mathrm{cde}$ \\
Eucalyptus grandis - A & $10,0 \pm 0,03 \mathrm{cde}$ \\
Eucalyptus grandis - D & $15,0 \pm 0,05 \mathrm{cde}$ \\
Eucalyptus grandis - E & $7,5 \pm 0,08 \mathrm{cde}$ \\
Melia azedarach (folha) - H & $12,5 \pm 0,13 \mathrm{cde}$ \\
Ocimum basilicum - E & $17,5 \pm 0,14 \mathrm{cde}$ \\
Ocimum basilicum - H & $10,0 \pm 0,04 \mathrm{cde}$ \\
Tagetes erecta - H & $16,3 \pm 0,17 \mathrm{cde}$ \\
Melia azedarach (folha) - A & $3,8 \pm 0,05 \mathrm{de}$ \\
Annona muricata - E & $2,5 \pm 0,06 \mathrm{e}$ \\
Melia azedarach (fruto) - A & $2,5 \pm 0,06 \mathrm{e}$ \\
Melia azedarach (fruto) - E & $1,3 \pm 0,05 \mathrm{e}$ \\
Ocimum basilicum - A & $1,3 \pm 0,05 \mathrm{e}$ \\
Ocimum basilicum - D & $2,5 \pm 0,06 \mathrm{e}$ \\
Ruta graveolens - A & $0,0 \pm 0,00 \mathrm{e}$ \\
Tagetes erecta - A & $1,3 \pm 0,05 \mathrm{e}$ \\
Tagetes erecta - D & $1,3 \pm 0,05 \mathrm{e}$ \\
Tagetes erecta - E & $2,5 \pm 0,06 \mathrm{e}$ \\
Controle & $0,0 \pm 0,00 \mathrm{e}$ \\
\hline -Mediaseguidasdemesma &
\end{tabular}

*Médias seguidas de mesma letra, na coluna, não diferem entre si pelo teste de Tukey $(\mathrm{P}<0,05)$.

$\mathrm{E}=$ etanol, $\mathrm{D}=$ diclorometano, $\mathrm{H}=$ hexano, $\mathrm{A}=$ água

Verificou-se que o óleo comercial de $A$. indica apresentou maior ação inseticida sobre adultos de $A$. diaperinus, sendo sua eficiência comprovada previamente em laboratório também contra larvas do mesmo inseto (SZCZEPANIK, 2001). Segundo a autora, larvas de 1ínstar alimentadas com ração para aves tratada com uminseticida comercial à base denim (Neem-Azal-T®) nas concentrações de 0,01 e $0,1 \%$ morreram após 25 e 45 dias, respectivamente, mostrandouma açãolenta. A azadiractina é o principal composto do nim, responsá- 
vel pelo efeito tóxico, assim como pelo efeito deterrente alimentar (Mordue (LunTz); NisBet, 2000).

Para $M$. azedarach, C. ambrosioides e R. graveolens observou-se diferença na mortalidade entre os extratos de diferentes solventes, sendo que dentre os extratos de folha de $M$. azedarach, apenas o diclorometânico e o etanólico apresentaram efeito. Com relação à C. ambrosioides, o extrato hexânico teve efeito significativo, sendo que Peterson et al. (1989) haviam constatado o efeito desse extrato sobre $S$. zeamais. Já o extrato aquoso não apresentou efeito sobre o cascudinho. TAVAREs (2006) testou o extrato aquoso da mesma planta sobre o gorgulho e também não observou efeito, sugerindo então que os compostos com atividade inseticida presentes em $C$. ambrosioides são extraídos apenas com solventes de média ou baixa polaridade.

O extrato etanólico de R.graveolens foi responsável pela maior mortalidade de $A$. diaperinus após onim, já o extrato aquoso não apresentou atividade inseticida, confirmando a questão da diferença de afinidade dos solventes em relação aos diferentes compostos das plantas, sendo importante comparar extratos obtidos em diferentes solventes. Em plantas da família Rutaceae, os compostosinseticidas são os limonoides e furanocumarinas (VIEIRA et al., 2001).

Na comparação dos extratos etanólicos de diferentes partes de M. azedarach (folha e fruto), observouse que houve mortalidade significativa dos insetos apenas quando foram utilizadas as folhas. Os extratos aquosos de ambas as estruturas não diferiram. Segundo SouZA; VENDRAMIM (2001), a variação no efeito de uma planta inseticida em função da estrutura vegetal utilizada para o preparo do extrato pode ser devido ao fato de os compostos inseticidas não estarem distribuídos uniformemente por toda a planta, como também relatado por Costa et al. (2004). Assim como o nim, o cinamomo tem como principal composto inseticida a azadiractina, além de salanina, meliatriol e nimbina (SCHMUTTERER, 1990).

Embora haja relatos na literatura de atividade biológica dos extratos das demais plantas testadas sobrealguns insetos, no presente estudo não se observou efeito sobre a sobrevivência de $A$.diaperinus.Ofato de se tratar de outro inseto, assim como o tipo de extrato utilizado ou a forma de aplicação são fatores que podem ter sido responsáveis pela ausência de efeito sobre o cascudinho.

Assim, como o óleo comercial de nim apresentou o melhor resultado, foi selecionado para os testes posteriores.

Comparação entre métodos de aplicação. Verificou-se diferença significativa entre os métodos de aplicação do óleo comercial de nim, tratamento com melhor resultado no primeiro experimento. No método de pulverização, houve mortalidade de $100 \%$ dos insetos tratados com o óleo, enquanto no método de contato a mortalidade foi de $40,9 \%$ para o mesmo tratamento (Fig. 1).

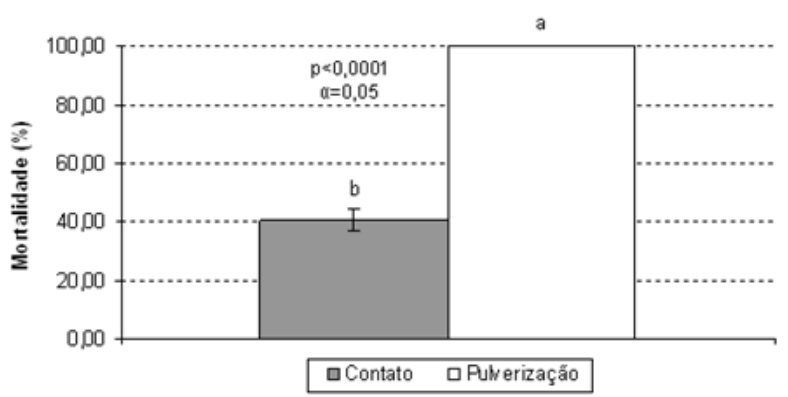

Fig. 1 - Comparação entre dois métodos de aplicação de óleo de nim comercial a $10 \%$ sobre adultos deA.Diaperinus, após 10 dias $\left(26 \pm 1^{\circ} \mathrm{C}\right.$ e fotofase $\left.14 \mathrm{~h}\right)$.

TABASSUM et al. (1998) já haviam demonstrado o efeito de contato de nim sobre o cascudinho. Eles testaram uma formulação de extrato de nim (RB-a) dissolvido em metanol $80 \%$, com butóxido de piperonila $0,01 \%$ e Triton $x-100$ 0,05\% (espalhante) em diferentes doses, aplicando sobre placas de Petri, tal como no presente estudo. A maior mortalidade após 24 horas foi de $70 \%$ na maior concentração testada $\left(117,8 \mu \mathrm{g}\right.$ da formulação de $\left.\mathrm{nim} / \mathrm{cm}^{2}\right)$.

As duas formas de aplicação são eficientes em relação ao nim, tendo destaque a pulverização sobre o inseto, uma vez que nesse método a exposição do inseto é maior, pois recebe aplicação do extrato em toda a superfície do corpo, podendo este penetrar por qualquer parte da cutícula. Já no método de contato, principalmente o tarso fica em contato com o extrato.

Atividade do óleo de nim em diferentes concentrações. Observou-se relação direta entre o aumento da concentração e o acréscimo da mortalidade dos insetos (Fig. 2). Na concentração de $0,1 \%$ o óleo de nim não apresentou ação inseticida, enquanto que nas concentrações de 1, 5 e 10\% houve, respectivamente, $31,6,73,8$ e $87,0 \%$ de mortalidade.

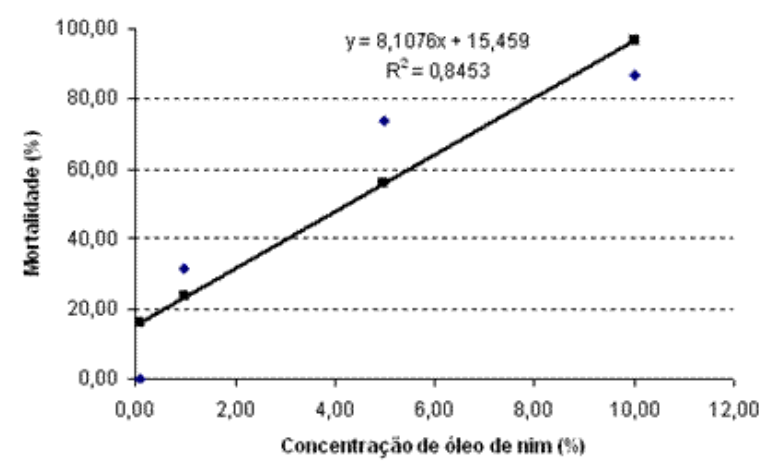

Fig 2 - Mortalidade de adultos de A. Diaperinus, 7 diasapós o tratamento com óleo comercial de nim em diferentes concentrações $\left(26 \pm 1^{\circ} \mathrm{C}\right.$ e fotofase $\left.14 \mathrm{~h}\right)$. 
TABASSUM et al. (1998) também obtiveram valores crescentes de mortalidade de adultos de cascudinho conforme aumentavam a concentração aplicada, porém sobre uma superfície com a qual o inseto entrava em contato.

Como a mortalidade causada pelas concentrações 5e10\% foi muito próxima, a menor delas foi escolhida para o teste em cama de aviário, visando utilizar menor quantidade do produto, sem no entanto causar grande redução no efeito.

Atividade do óleo de nim em cama de aviário. Houve diferença entre as aplicações do óleo de nim na concentração de $5 \%$ antes e após a liberação dos insetos, entretanto a mortalidade foi muito pequena em ambos os tratamentos, não sendo verificado efeito inseticida do nim nas condições avaliadas (Fig. 3). A cama pode ter impedido o contato direto do produto com o inseto, reduzindo ou mesmo eliminando seu efeito. $O$ fato de o inseto ser fototrópico negativo e se esconder no fundo do pote pode ter contribuído para redução do contato com o produto, que ficou principalmente na superfície da cama.

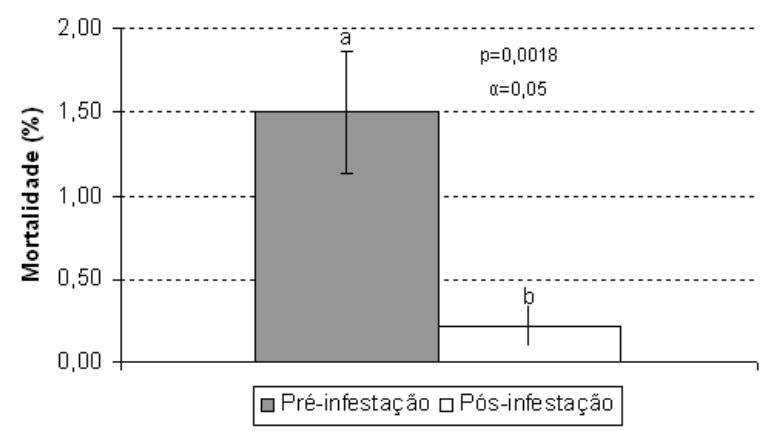

Fig 3 - Efeito do óleo de nim a 5\% sobre adultos de $A$. Diaperinus, aplicados na cama de aviário usada, antes e depois da infestação, após 7 dias ( $26 \pm 1^{\circ} \mathrm{C}$ e fotofase $\left.14 \mathrm{~h}\right)$.

O tratamento da cama com produtos químicos ou mesmo com o fungo entomopatogênico Beauveria bassiana, para o controle de $A$. diaperinus não tem se mostrado um método eficiente, levando a resultados insatisfatórios (BACON, 1986; GEDENetal., 1987; AlEXANDRE et al., 2006). Dentre as prováveis causas para a ineficácia, têm-se as alterações físicas, químicas e biológicas que ocorrem na cama usada do aviário que podem interferir na atividade do agente de controle. A presença de compostos orgânicos e de um $\mathrm{pH}$ elevado na cama de aviário reduzem a eficácia dos inseticidas químicos (Arends, 1987; Steelman, 1996). Como no presente estudo foi utilizada cama de aviário usada, esta poderia ter sofrido alterações, como citado acima, que tenham interferido nas propriedades inseticidas do óleo de nim. Isso explicaria o fato de o produto não ter apresentado o mesmo efeito que nos tratamentos sem cama dos experimentos anteriores.
O fato de não ter sido observado efeito inseticida do óleo comercial de nim no período avaliado em cama de aviário não implica na ausência de efeitos negativos sobre esse inseto, como interferência na reprodução, oviposição ou alimentação, reduzindo a população de $A$. diaperinus a longo prazo, como já foi relatado por SZCZEPANIK (2001). Como tais efeitos não foram avaliados no presente estudo, recomenda-se que sejam objetivo de experimentos futuros.

\section{CONCLUSÕES}

Os extratos etanólico de folhas de R. graveolens, hexânico de ramos deC. ambrosioides, diclorometânico e etanólico de folhas de $M$. azedarache, particularmente o produto à base de óleo de sementes de $A$. indica, apresentam propriedades inseticidas contra $A$. diaperinus, apresentando potencial para serem utilizados como uma ferramenta no manejo dessa praga. A determinação da concentração e da forma de aplicação são importantes, pois interferem na ação, como demonstrado com o óleo de nim, que apresenta maior efeito para o cascudinho quando pulverizado sobre ele e em concentrações acima de $1 \%$.

$\mathrm{O}$ nim não apresenta efeito quando aplicado na cama de aviário usada, antes ou após a infestação, entretanto mais estudos são necessários nesse sentido, pois o teste realizado em laboratório expressa muito pouco do que é a realidade de um aviário.

\section{AGRADECIMENTOS}

À Fundação Araucária pelo financiamento da pesquisa, e ao CNPq pela concessão de bolsas de IC e Produtividade, durante a realização do trabalho.

\section{REFERÊNCIAS}

ALVES, S.B.; HADDAD, M.L.; MORAES, R.C.B.; REYES, A.E.L. Utilização de fórmulas para correção de mortalidade. Disponível em: <http:/ /www.lef.esalq.usp.br/ cm/intro.php>. Acesso em: 10 set. 2005.

ABBOTT, W. S. A method of computing the effectiveness of an insecticide. Journal of Economic Entomology, v.18, p.265-266, 1925.

ALEXANDRE, T.M.; ALVES, L.F.A.; NEVES, P.M.O.J.; ALVES, S.B. Efeito da temperatura e cama do aviário na virulência de Beauveria bassiana (Bals.) Vuill. e Metarhizium anisopliae (Metsch.) para o controle do cascudinho (Alphitobius diaperinus) (Panzer) (Coleoptera: Tenebrionidae). Neotropical Entomology, v.35, n.1, p.75-82, 2006. 
ALMEIDA, F.A.C.; GOLDFARB, A.C.; GOUVEIA, J.P.G. Avaliação de extratos vegetais e métodos de aplicação no controle de Sitophilus spp. Revista Brasileira de Produtos Agroindustriais, v.1, n.1, p.13-20, 1999.

ALVES, L.F.A.; BUZARELLO, G.D.; OLIVEIRA, D.G.P.; ALVES, S.B. Ação da terra de diatomácea contra adultos do cascudinho Alphitobius diaperinus (Panzer, 1797) (Coleoptera: Tenebrionidae). Arquivos do Instituto Biológico, São Paulo, v.73, n.1, p.115-118, 2006.

ARENDS, J.J. Control, management of the litter beetle. Poultry Digest, v.44, p.172-176, 1987.

AXTELL, R.C.; ARENDS, J.J. Ecology and management of arthropod pests of poultry. Annual Review of Entomology, v.35, p.101-126, 1990.

BACON, C.W. Effects of broiler litter volatiles and ammonia on fungal spore germination. Poultry Science, v.65, p.710-716, 1986.

CARVALHO, S.M.; FERREIRA, D.T. Santa-Bárbara contra a vaquinha. Ciência Hoje, v.11, n.65, p.65-67, 1990.

CHERNAKI-LEFFER, A.M.; ALMEIDA, L.M. Exigências térmicas, período de desenvolvimento e sobrevivência de imaturos de Alphitobius diaperinus (Panzer) (Coleoptera: Tenebrionidae). Neotropical Entomology, v.30, n.3, p.365-368, 2001.

CHERNAKI-LEFFER, A.M.; LAZZARI, F.A.; LAZZARI, S.M.N.; ALMEIDA, L.M. Controle do cascudinho. Avicultura Industrial, v.92, n.1094, p.22-25, 2001.

CHERNAKI-LEFFER, A.M.; BIESDORF, S.M.; ALMEIDA, L.M.; LEFFER, E.V.B.; VIGNE, F. Isolamento de enterobactérias em Alphitobius diaperinus e na cama de aviários no Oeste do estado do Paraná, Brasil. Revista Brasileira de Ciência Avícola, v.4, p.243-247, 2002.

COSTA, E.L.N.; SILVA, R.F.P.; FIUZA, L.M. Efeitos, aplicações e limitações de plantas inseticidas. Acta Biologica Leopoldensia, v.26, n.2, p.173-185, 2004.

GEDEN, C.J.; EDWARDS, T.D.; ARENDS, J.J.; AXTELL, R.C. Efficacies of mixtures of disinfectants and insecticides. Poultry Science, v.66, p.659-665, 1987.

GOODWIN, M.A.; WALTMAN, W.D. Transmission of Eimeria, viruses, and bacteria to chicks: Darkling beetles (Alphitobius diaperinus) as vector of pathogens. Journal of Applied Poultry Research, v.5, p.51-55, 1996.

HASAN, M.M.; PARWEEN, S.; REZA, A.M.S.; NILUFAR, E. Combined action of Derris indica Bennet either with a bacterium or with an insect growth regulator on mature larvae of Alphitobius diaperinus Panzer (Coleoptera: Tenebrionidae). International Pest Control, v.44, n.3, p.128-131, 2002.
LAMBKIN, T.A. Baseline responses of adult Alphitobius diaperinus (Panzer) (Coleoptera: Tenebrionidae) to fenitrothion, and susceptibility status of populations in Queensland and New South Wales, Australia. Journal of Economic Entomology, v.98, p.938-942, 2005.

LEATEMIA, J.A.; ISMAN, M.B. Efficacy of crude seed extracts of Annona squamosa against diamondback moth, Plutella xylostella L. in the greenhouse. International Journal of Pest Management, v.50, n.2, p.129133, 2004.

MAZZONETTO, F.; VENDRAMIM, J.D. Efeito de pós de origem vegetal sobre Acanthoscelides obtectus (Say) (Coleoptera: Bruchidae) em feijão armazenado. Neotropical Entomology, v.32, n.1, p.145-149, 2003.

MORDUE (LUNTZ), A.J.; NISBET, A.J. Azadirachtin fron the neem tree Azadirachta indica: its action against insects. Annais da Sociedade Entomológica do Brasil, v.29, n.4, p.615-632, 2000.

PETERSON, G.S.; KANDIL, M.A.; ABDALLAH, M.D.; FARAG, A.A.A. Isolation and characterization of biologically active compounds from some plants extracts. Pesticide Science, v.25, p.337-342, 1989.

RAHMAN, M.A.; AHMAD, M.; SHAHJAHAN, M. Effectiveness of some indigenous plant seed oils against the lesser meal worm, Alphitobius diaperinus (Panzer) (Col.: Tenebrionidae). Bangladesh Journal of Entomology, v.11, n.1-2, p.41-54, 2001.

RODRÍGUEZ, H.C.; VENDRAMIM, J.D. Toxicidad de extractos acuosos de Meliaceae en Spodoptera frugiperda (Lepidoptera: Noctuidae). Manejo Integrado de Plagas, v.42, p.14-22, 1996.

SAS INSTITUTE Inc. SAS System for Microsoft Windows, 9.1.Cary, NC, USA, 2004.

SCHMUTTERER, H. Properties and potential of natural pesticides from the neem tree, Azadirachta indica. Annual Review of Entomology, v.35, p.271-297, 1990.

SHOWLER, A.T.; GREENBERG, S.M.; ARNASON, J.T. Deterrent effects of four neem-based formulations on gravid female boll weevil (Coleoptera:

Curculionidae) feeding and oviposition on cotton squares. Journal of Economic Entomology, v.97, n.2, p.414421, 2004.

SOUZA, A.P.; VENDRAMIM, J.D. Atividade inseticida de extratos aquosos de meliáceas sobre a mosca-branca Bemisia tabaci (Genn.) biótipo B (Hemiptera:

Aleyrodidae). Neotropical Entomology, v.30, p.133-1371, 2001.

STEELMAN, D. Darkling beetles are costly pests. Poultry Digest, v.55, n.10, p.22-23, 1996. 
SZCZEPANIK, M. Studies on the biological activity of azadirachtin lesser mealworm, Alphitobius diaperinus Panzer. In: KONOPINSKA, D. (Ed.) Arthropods Chemical, physiological and environmental aspects. Poland: University of Wroclaw, 2001. p.228-233.

TABASSUM, R.; NAQVI, S.N.H.; JAHAN, M.; NURULAIN, S.M.; KHAN, M.F.; AZMI, M.A. Determination of the toxicities of fenpropathrin (pyrethroid) and neem formulation (RB-a + PBO + Tx100) against Alphitobius diaperinus adults and their effects on transaminases. Turkish Journal of Zoology, v.22, n.4, p.319-322, 1998.

TAVARES, M. A. G. C. Busca de compostos em Chenopodium spp. (Chenopodiaceae) com bioatividade em relação a pragas de grãos armazenados. 2006. 111f. Tese (Doutorado em Ciências - Área de concentração: Entomologia) - Escola Superior de Agricultura Luiz de Queiroz, Piracicaba, 2006.
TORRES, A.L.; BARROS, R.; OLIVEIRA, J.V. Efeito de extratos aquosos de plantas no desenvolvimento de Plutella xylostella (L.) (Lepidoptera: Plutellidae). Neotropical Entomology, v.30, n.1, p.151-156, 2001.

VIEIRA, P.C.; MAFEZOLI, J.; BIAVATTI, M.W. Inseticidas de origem vegetal. In: FERREIRA, J.T.B.; CORREA, A.G.; VIEIRA, P.C. (org.). Produtos naturais no controle de insetos. São Carlos: Editora da UFSCar, 2001. p.23-46.

VITTORI, J.; SCHOCKEN-ITURRINO; R.P.; TROVÓ, K.P.; RIBEIRO; C.A.M.; BARBOSA, G.G.; SOUZA, L.M.;

PIGATTO, C.P. Alphitobius diaperinus como veiculador de Clostridium perfingens em granjas avícolas do interior paulista. Ciência Rural, v.37, n.3, p.894-896, 2007.

Recebido em 22/3/08

Aceito em 18/5/09 